\title{
Development of equipment for the monitoring system of the Baikal water area
}

\author{
Roman Belousov ${ }^{1}$, Andrey Nikolaev ${ }^{1, *}$, Eugene Fiskin ${ }^{1}$, and Margarita Fiskina ${ }^{1}$ \\ ${ }^{1}$ Irkutsk National Research Technical University, 83, Lermontov street, Irkutsk, Russia
}

\begin{abstract}
Abstrsct. This article is devoted to the development of a monitoring system of Lake Baikal. The developed system should provide ongoing monitoring of hydrophysical parameters of water in different areas of the lake, which will allow identifying signs of environmental pollution of Lake Baikal timely. A distinctive feature of the created system is high productivity at low economic costs per accounting point. The appropriate selection of the component base and software optimization of algorithms will allow achieving the maximum range of data transmission at a distance of up to 100 $\mathrm{km}$ in an open area. The interim results of the monitoring system development are presented, the tasks for the current year are defined.
\end{abstract}

\section{Introduction}

Today, the problem of conservation of ecology is very acute, due to the gradually increasing influence of the anthropogenic factor on the environment.

The largest repository of drinking water on earth is Lake Baikal, which currently requires constant monitoring of the level of water pollution and adjacent territories.

By presidential decree, the government until 2024 must:

1) To ensure the ecological improvement of water bodies, including the Volga River, and the preservation of unique water systems, including Lake Baikal and Teletskoe [1];

2) Solve the problem of preserving unique water bodies, including implementing a project to preserve Lake Baikal, as well as measures to clean the shores of the shores and coastal waters of Lake Baikal, Teletskoye, Ladoga, Onega and the Volga, Don, Ob, Yenisei, Amur, Ural rivers, Pechora, and, possibly, to develop a system of timely warning and routine monitoring of the state of the lake water area.

To begin with, we reviewed the existing data collection systems.

The monitored monitoring systems are mainly designed for indoor installation and do not have an independent power source and built-in data transmission system via a radio channel, but are more focused on storing the received data in the device's memory, which in this case is not entirely relevant due to difficult data collection from monitoring devices.

The presented systems do not have a built-in battery and are not designed for full autonomous operation. Power is usually supplied from the industrial network of $220 \mathrm{~V}$.

Below is a comparative table of existing systems.

\footnotetext{
${ }^{*}$ Corresponding author: nikolaev94@icloud.com
} 
Table 1. Comparison of existing monitoring systems

\begin{tabular}{|c|c|c|c|c|c|c|c|}
\hline Name & ИТП & 2ТРМ0 & BM8034 & ТPM200 & ИДЦ1 & УКТЗ8 & $\begin{array}{c}\text { testo } \\
\text { Saveris } \\
\text { TM } \\
\end{array}$ \\
\hline $\begin{array}{c}\text { Number of } \\
\text { inputs }\end{array}$ & 1 & 2 & 8 & 2 & 1 & 8 & 15 \\
\hline $\begin{array}{l}\text { Support for } \\
\text { sensor types }\end{array}$ & \multicolumn{7}{|c|}{ Digital, analog } \\
\hline $\begin{array}{l}\text { Supply } \\
\text { voltage }\end{array}$ & 24 & 220,24 & $3 \times \mathrm{AA}$ & 220 & 24 & 220 & $\begin{array}{c}\text { DC 6.3, } \\
\text { AC } 24\end{array}$ \\
\hline $\begin{array}{c}\text { Battery life, } \\
\text { years }\end{array}$ & - & - & 3 & - & - & - & - \\
\hline $\begin{array}{c}\text { Operating } \\
\text { frequency, } \\
\text { MHz }\end{array}$ & $\begin{array}{c}\text { No built-in } \\
\text { modem }\end{array}$ & $\begin{array}{c}\text { No built-in } \\
\text { modem }\end{array}$ & WiFi & $\begin{array}{c}\text { No built-in } \\
\text { modem }\end{array}$ & $\begin{array}{l}\text { No built-in } \\
\text { modem }\end{array}$ & $\begin{array}{l}\text { No built-in } \\
\text { modem }\end{array}$ & GSM \\
\hline Cost, RUB & 2006 & 3127 & 3690 & 3835 & 4307 & 8201 & 49000 \\
\hline
\end{tabular}

It was also considered similar to the tasks wireless dispatching system based on LoRaWAN - Network 868. The operating frequency is in a license-free radio band of 868 $\mathrm{MHz}$ with a data transfer rate of $292 \mathrm{bps}$. The range of data transmission in urban areas ranges from 2.5 to $4 \mathrm{~km}$; the transmitter power is not more than $25 \mathrm{~mW}$ [2]. The scheme of data collection from apartment metering devices is shown in Figure 1.

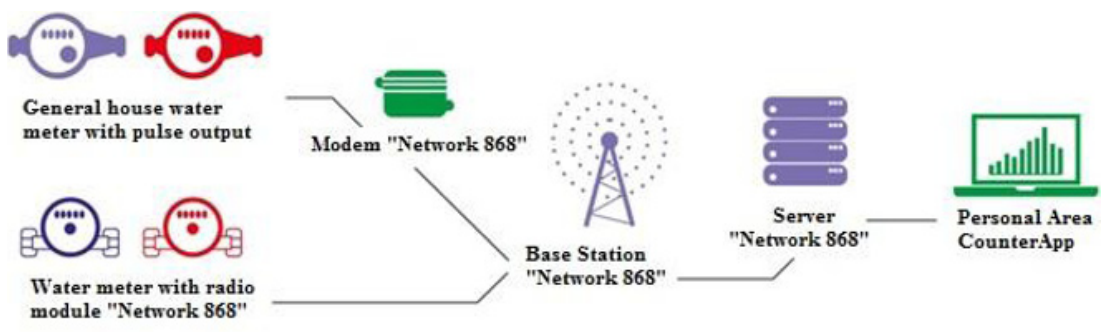

Fig. 1. Data Acquisition and Transmission Scheme

Despite the effectiveness of the "Network 868" several shortcomings are noted:

1) Relatively low bandwidth due to the use of low-frequency radio channel varies depending on the technology used to transmit data at the physical level and ranges from several hundred bits/s to several tens of $\mathrm{kbit} / \mathrm{s}$.

2) the Delay of data transmission from the sensor to the final application, related to the time of transmission of the radio signal, can reach from a few seconds to several tens of seconds.

3) No single standard defines the physical layer and media access control for wireless LPWAN networks.

4) placement of the hub at low altitudes leads to a decrease in the radius and speed of data transmission;

5) Poor antenna and poor installation also reduce the radius and speed of data transmission;

6) Proximity GSM-900 equipment leads to interference in the radio channel. 
To solve existing problems, it was decided to develop its own monitoring system for the Baikal water area, consisting of sensors for analyzing the hydrophysical characteristics of water, a radio modem, a hub, and a GSM module.

\section{Proposed Monitoring System}

The radio modem developed by the STC "Kumir" company and intended for the apartmentbased accounting of data was taken as the basis[3-6]. The appearance of the radio modem is shown in Figure 3.

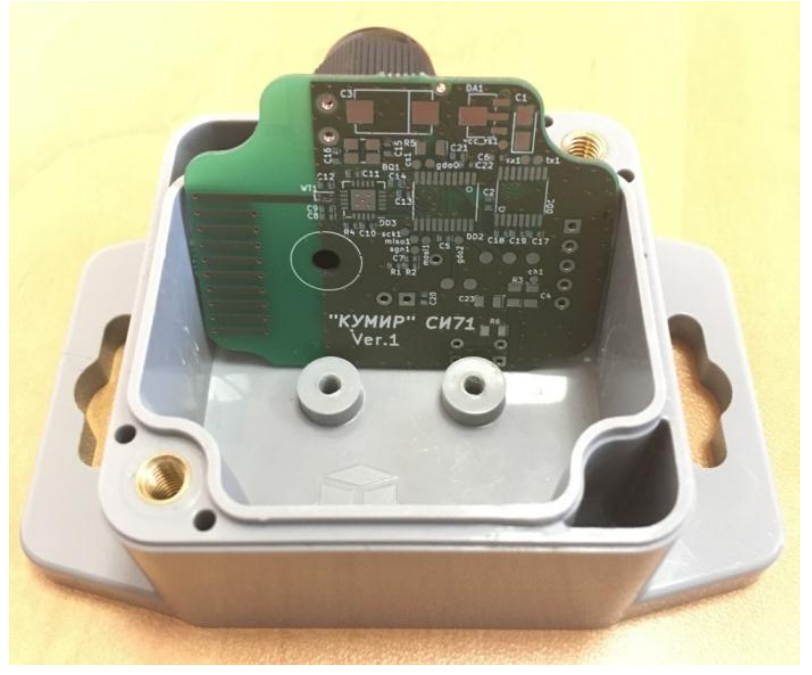

Fig. 2. Radio modem developed in the STC "Kumir"

A distinctive feature of the radio modem taken is low power consumption due to the use of the CC1120 transceiver, the presence of an integrated power supply and the ability to transmit data over a radio channel at a frequency of $868 \mathrm{MHz}$ with a data transfer rate of 1.2 Kbps [7-9].

To date, communications have been tested in open areas. As a result, the range of stable data transmission was $6 \mathrm{~km}$.

Further modernization of the existing system for monitoring the water area of Lake Baikal consists in adapting the radio modem to work with water analysis sensors and increasing the range of a stable connection with the concentrator from the existing $6 \mathrm{~km}$ to $20-100 \mathrm{~km}$ on Lake Baikal.

The task of increasing the communication range is divided into the following stages: 1) Increased transmitter power; 2) Use of thermostable components; 3) Increase receiver sensitivity; 4) Use a single wave (directional) antenna.

A more powerful amplifier CC1190 can be applied on the territory of the Russian Federation, in connection with Appendix No. 12 to the decision of the SCRF of September 11, 2018 No. 18-46-03-1 which states that the maximum EIM for $868 \mathrm{MHz}$ is $100 \mathrm{~mW}$.

This amplifier has a high output power of $27 \mathrm{dBm}$, which will allow at the stage of creating a prototype to achieve a data transmission distance of up to $114 \mathrm{~km}$ according to Texas Instruments $[8,10]$. 
Ensuring the stability of the parameters of the components used in the design of the highfrequency path of the transceiver will ensure the stability of the output parameters, high quality, and maximum data transmission distance.

To solve the problem of stabilization of parameters, it is planned to use radio components with a small value of the temperature coefficient.

The slightest temperature change in the dielectric thickness causes a substantial change in the capacitance of the capacitor.

Each type of capacitor has advantages and disadvantages. For example, electrolytic capacitors have a high specific capacity but have low-temperature stability, high series resistance, and low-frequency characteristics [11].

Accounting for all the above factors will allow you to create a system with low power consumption and the greatest range of sustainable data transmission.

The CC1120 is oriented towards a narrowband channel (i.e., the receiver band can be made from $8 \mathrm{kHz}$ ). The manufacturer does not recommend the use of this transceiver for operation at data rates greater than $100 \mathrm{kbps}$.

An important feature of the CC1120 transceiver is high sensitivity at a frequency of 868 $\mathrm{MHz}$ and is $-127 \mathrm{dBm}$, the maximum sensitivity when using special add-ons of the passport operation mode is $-135 \mathrm{dBm}$.

In addition to the power saving modes of the transceiver, a new radio channel listening mode (the so-called ChannelSniffMode) has become. For wireless network nodes, the current consumption in receive mode is one of the important indicators of energy efficiency. This issue is particularly acute for devices with autonomous power.

To reduce power consumption in the receive mode, the PerformanceLine introduces a new mode, RF ChannelShiffMode, which listens to the channel. RF mode ChannelShiffMode allows you to automatically detect activity in the radio channel. In this mode, the receiver automatically checks the channel for transmission at short intervals and then turns off, and the situation repeats in the next period of time. The receiver turn-on period is set smaller than the packet preamble length.

The receiver in the $\mathrm{CC} 112 \mathrm{x}$ requires only four bits of the preamble of the packet to establish the mode, including frequency offset compensation and automatic gain control the transition time from IDLE to receive (RX) mode is about $150 \mu \mathrm{s}$. The total time of receiver activity, starting from the start of the generator before listening to the air, is about $500 \mu \mathrm{s}$, with a total duration of the active phase of the cycle of about $670 \mu \mathrm{s}$ (depending on the current settings of the transceiver). Figure 3 illustrates the principle of operation of the receiver in the listening mode and the oscillogram of the current consumed.

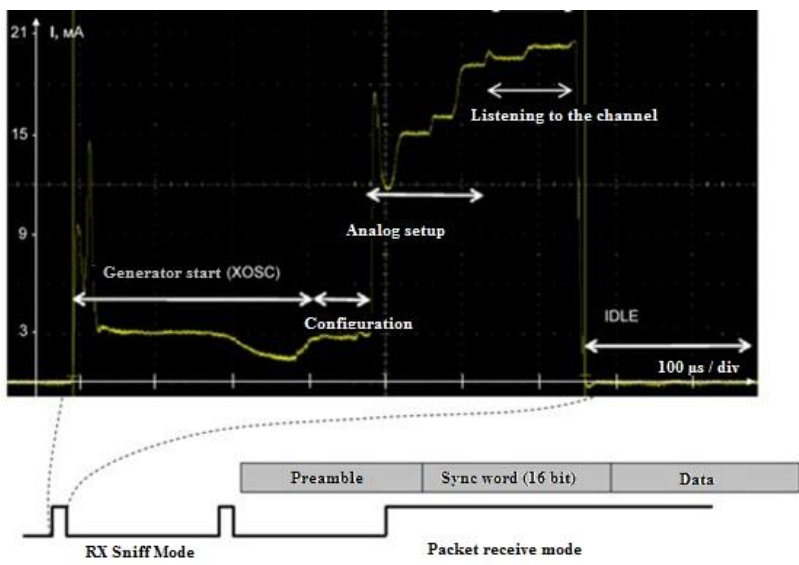

Fig. 3. RF Channel Shiff Mode listening mode 
The average consumption in receive mode will depend on the current transmission rate and the length of the preamble, but the gain is noticeable even at high speeds. So the use of this mode with a preamble length of 4 bits at a speed of $1.2 \mathrm{kbit} / \mathrm{s}$ reduces the receive consumption from $21 \mathrm{~mA}$ to $3 \mathrm{~mA}$, and at a speed of $50 \mathrm{kbit} / \mathrm{s}$ to $16 \mathrm{~mA}$.

In this work it is planned to use ARM microcontroller with Cortex-M core, which can easily compete with 8 and 16 bit controllers, such as AVR, PIC, MSP430, etc. [12]. In addition, for ARM microcontrollers, there are many debugging and programming tools, the prices of which are quite affordable even for purchase "for home use". For example, the official debug Board STM32VL Discovery has on Board the in-circuit debugger ST-LINK and debugged microcontroller STM32F100RBT with 128 Kbytes of flash memory, 8 Kbytes of RAM and $24 \mathrm{MHz}$ clock speed at retail costs 10-15 dollars.

ARM microcontrollers have much higher specifications and capabilities. At the moment, the most technologically advanced of this series can be called a microcontroller STM32F407, having 1 megabytes of ROM memory, 192 kilobytes of RAM memory and operating at a frequency of up to $168 \mathrm{MHz}$, while performing up to 210 million operations per second.

This combination of chips will create a powerful system for data transmission with low power consumption, which will work on a single battery size CR2032 for 5-6 years.

When choosing hydrological probes, we were guided by the following regulatory and technical documents [13-15]:

1) GOST 8.457-2015 GSI. State verification schedule for measuring the electrical conductivity of liquids.

2) GOST R 8.802-2012 GSI. State verification schedule for means of measuring excess pressure up to $250 \mathrm{MPa}$.

3) GOST 8.558-2009 GSI. State verification schedule for temperature measuring instruments.

\section{Further objectives of the Monitoring System Development}

Based on the technical characteristics of the hydrological probe, namely, the power parameters, it is proposed either to modernize and reduce the power consumption, or to develop our own hydrological probes on the basis of technical and metrological requirements.

At the moment, we are consulting with leading staff of the Federal State Budgetary Institution of Science "Limnological Institute of the Siberian Branch of the Russian Academy of Sciences" on issues related to measured water parameters when assessing the degree of pollution of Lake Baikal, as well as on the existing requirements for the water quality sensors themselves.

The monitoring system includes points of current monitoring of water parameters, concentrators, for receiving and processing data, a satellite data transmission system, for remote areas of the lake with poorly developed infrastructure.

Satellite Internet is the best solution to the problems of data transmission in remote areas, since the coverage area is $99 \%$ of the entire planet.

At the moment we are in the process of coordinating the modes of operation of the transceiver with the microcontroller, through software and hardware optimization.

This year, it is planned to conduct field trials in order to identify additional effects that affect data transmission in the water area of Lake Baikal and the search for solutions to eliminate them. 


\section{References}

1. The decree "On the national goals and strategic objectives of the development of the Russian Federation for the period up to 2024" [Electronic resource] // Decree: [site]. [2019] URL: http://kremlin.ru/events/president/news/57425. (date of the application 28.01.2019)

2. Development of LoRaWAN networks in Russia: wireless dispatching systems for utilities [Electronic resource] // Article: [site]. [2018] URL: https://controlengrussia.com/internet-veshhej/lorawan/ (date of the application 20.11.2018)

3. M.S. Sizykh, A.A. Nikolaev, A.A. Pinkin, Proc. of the All-Russian scientific-practical conference Improving the efficiency of production and use of energy in the conditions of Siberia, 2, 450 (2016)

4. R.A. Belousov, A.A. Pinkin, E.M. Fiskin, M.M. Fiskina, Proc. EURO-ECO 2015. Ökologische, Technologische und Rechtliche Aspekte der Lebensversorgung, 15 (2015)

5. R.A. Belousov, A.A. Pinkin, E.M. Fiskin, M.M. Fiskina, Proc. EURO-ECO 2014. Ökologische, Technologische und Rechtliche Aspekte der Lebensversorgung, 28 (2014)

6. R. Belousov, E. Fiskin, and M. Fiskina, E3S Web Conf., 39, ID: 04004 (2018)

7. http://www.ti.com/lit/ds/symlink/cc1120.pdf (date of the application 20.11.2018)

8. CC112x-CC1190 BoosterPack [Electronic resource] // Article: [site]. [2018]. URL: http://www.ti.com/lit/an/swra492/swra492.pdf (date of the application 28.11.2018)

9. http://www.ti.com/lit/an/swra407/swra407.pdf (date of the application 28.11.2018)

10. http://www.ti.com/lit/ds/symlink/cc1190.pdf (date of the application 28.11.2018)

11. N. Makhnov, Thermostable film capacitors of the $880 \mathrm{p}$ series from exxelia (Passive components, Moscow, 2018)

12. https://www.arm.com/products/silicon-ip-cpu (date of the application 28.11.2018)

13. GOST 8.457-2015 GSI (Standards Publishing House, Moscow, 2015)

14. GOST R 8.802-2012 GSI (Standards Publishing House, Moscow, 2012)

15. GOST 8.558-2009 GSI (Standards Publishing House, Moscow, 2009) 